\title{
Clonality and altered behavior of endothelial cells from hemangiomas
}

\author{
Eileen Boye, ${ }^{1}$ Ying Yu, ${ }^{2}$ Gretchen Paranya, ${ }^{2}$ John B. Mulliken, ${ }^{3}$ \\ Bjorn R. Olsen, ${ }^{1}$ and Joyce Bischoff ${ }^{2}$ \\ ${ }^{1}$ Department of Cell Biology, Harvard Medical School, and Harvard-Forsyth Department of Oral Biology,
Harvard School of Dental Medicine, Boston, Massachusetts, USA
${ }^{2}$ Department of Surgery, and
${ }^{3}$ Division of Plastic Surgery, Children's Hospital, Boston, Massachusetts, USA
}

Address correspondence to: Joyce Bischoff, Department of Surgery, Children's Hospital, 300 Longwood Avenue, Boston, Massachusetts 02115, USA. Phone: (617) 355-7865; Fax: (617) 355-7043; E-mail: joyce.bischoff@tch.harvard.edu.

Received for publication September 27, 2000, and accepted in revised form January 18, 2001.

\begin{abstract}
Hemangioma, the most common tumor of infancy, is a benign vascular neoplasm of unknown etiology. We show, for the first time to our knowledge, that endothelial cells from proliferating hemangioma are clonal, and we demonstrate that these hemangioma-derived cells differ from normal endothelial cells in their rates of proliferation and migration in vitro. Furthermore, migration of hemangioma endothelial cells is stimulated by the angiogenesis inhibitor endostatin, unlike the inhibition seen with normal endothelial cells. We conclude that hemangiomas constitute clonal expansions of endothelial cells. This is consistent with the possibility that these tumors are caused by somatic mutations in one or more genes regulating endothelial cell proliferation.
\end{abstract}

J. Clin. Invest. 107:745-752 (2001).

\section{Introduction}

Cutaneous hemangiomas occur in 5-10\% of Caucasian infants. The lesions are benign tumors of vascular endothelial cells (ECs) that exhibit a predictable evolution and duration. Typically, they are not apparent at birth, but appear around the second week of life, grow rapidly over the next 6-10 months (proliferating phase), and then slowly regress over the next $7-10$ years (involuting phase) (1). Most hemangiomas are small lesions, but about $10 \%$ grow rapidly and because of their size and/or location can be problematic and even life threatening. The proliferating and involuting phases of the hemangioma "life cycle" are not distinct, but represent a gradual shift in the balance of mitotic and apoptotic activity in the local EC population. The mitotic rate is high during the proliferating phase, and extensive pockets of rapidly proliferating ECs are observed. During the early involuting phase (1-2 years of age), mitosis gradually diminishes and apoptosis predominates, with ECs making up about a third of the dying cells (2).

The nature and cellular location of the primary defect responsible for triggering, maintaining, and arresting this abnormal endothelial proliferation are unknown. The defect could either be an inherent characteristic of the ECs themselves (3) or a secondary response to an external abnormality, such as the upregulation of an angiogenic factor or the downregulation of an angiostatic factor, in the immediate environment of the tumor (4). The former hypothesis would implicate a somatic mutation in a factor involved in control of EC proliferation. This hypothesis requires that all the ECs in the lesion originate from the same progenitor cell, i.e., be clonal, and carry a somatic mutation that causes abnormal proliferation. Additionally, it predicts that these mutated cells would behave differently from normal ECs and maintain these differences independently of their normal physiological environment. The alternative extrinsic hypothesis predicts that ECs in hemangioma are polyclonal and behave similarly to normal ECs when removed from their in vivo environment.

In an attempt to elucidate the molecular pathogenesis of hemangiomas, we tested the intrinsic hypothesis, i.e., that the tumors are caused by clonal expansion of vascular ECs. We isolated ECs from proliferating hemangioma in nine infants and from multifocal hemangioendothelioma lesions in one infant. We assayed cell samples from eight of the ten patients for monoclonality and found all to be clonal. We further demonstrated that hemangioma-derived ECs differ from normal ECs in rate of proliferation and migration in vitro, as well as in their response to an angiogenesis inhibitor endostatin.

Our results indicate that hemangiomas do indeed constitute clonal expansions of abnormal ECs. The findings are consistent with the possibility that hemangiomas are caused by somatic mutation(s) in a gene(s) that regulates EC proliferation.

\section{Methods}

Patient material. Proliferating-phase hemangioma specimens were obtained from nine female infants. The patients' ages at the time of resection, the location and size of the lesion(s), any prior treatment, and other relevant clinical information are given in Table 1. In addi- 
tion, a patient (patient 8) with multiple high-grade hemangioendothelioma (heoma) lesions of variable size was included in the study. Normal skin samples were obtained from age-matched female infants undergoing other surgical procedures in which these tissues would have been discarded. The tissue specimens were identified by age and gender only, in accordance with the protocol approved by the Committee on Clinical Investigation at Children's Hospital, Boston, and were collected and processed immediately after resection.

Normal blood samples from 40 age-matched female infants, from a pool of samples left over from routine hematological tests, were obtained from the Hematology Laboratory at Children's Hospital, Boston, in accordance with the protocol approved by the Committee on Clinical Investigation. These samples were identified by the child's age and gender only.

Isolation, culture, and characterization of hemangioma-derived ECs. ECs were isolated from hemangiomas (hemECs) and normal skin (HFSECs) by the method described previously by Kräling and Bischoff (5) for human dermal microvascular ECs (HDMECs). The only modification was trypsinization of the hemangioma tissue for $4 \mathrm{~min}$ utes at $37^{\circ} \mathrm{C}$ instead of 10 minutes. The cells were resuspended in EBM-A (EBM131 (Clonetics, San Diego, California, USA), 20\% heat-inactivated FBS (Hyclone Laboratories, Logan, Utah, USA), 2 mM glutamine, 100 $\mathrm{U} / \mathrm{ml}$ penicillin, $100 \mu \mathrm{g} / \mathrm{ml}$ streptomycin (Irvine Scientific, Santa Ana, California, USA), $0.25 \mu \mathrm{g} / \mathrm{ml}$ amphotericin B (Life Technologies Inc., Gaithersburg, Maryland, USA), $0.5 \mathrm{mM} \mathrm{N}-6,2^{\prime}$-O-dibutyryladenosine $3^{\prime}: 5^{\prime}$-cyclic monophosphate (Sigma Chemical Co., St. Louis, Missouri, USA), $1.0 \mu \mathrm{g} / \mathrm{ml}$ hydrocortisone (Sigma Chemical Co.) and grown overnight at $37^{\circ} \mathrm{C}$ with $5 \% \mathrm{CO}_{2}$, washed vigorously with PBS to remove unattached cells, and fed with fresh EBM-A. These primary cultures were grown to preconfluence (5-7 days). The ECs were purified from the primary culture using Ulex europaeus I lectin-coated (Vector Laboratories Inc., Burlingame, California, USA) magnetic beads (Dynal A.S., Lake Success, New York, USA), as described by Jackson et al. (6). ECs bound to the lectincoated beads were collected with a magnetic particle concentrator, and any unbound cells were removed with five washes in HBSS wash buffer $(5 \% \mathrm{FBS}, 100 \mathrm{U} / \mathrm{ml}$ penicillin, $100 \mu \mathrm{g} / \mathrm{ml}$ streptomycin [Irvine Scientific, Santa Ana, California, USA], and $0.25 \mu \mathrm{g} / \mathrm{ml}$ amphotericin B [Life Technologies Inc.]). The ECs and unbound fibroblast-like cells (UBCs) were separately resuspended in EBM-A and grown to confluence on gelatin-coated 60$\mathrm{mm}$ plates. To expand further the purified cultures after $\mathrm{P} 2$, the cells were passaged 1:3 into a simplified medium EBM-B (EBM131, 10\% heat inactivated FBS, 2 mM glutamine, $100 \mathrm{U} / \mathrm{ml}$ penicillin, $100 \mu \mathrm{g} / \mathrm{ml}$ streptomycin, 2 $\mathrm{ng} / \mathrm{ml}$ bFGF [kindly provided by Scios Inc., Mountain View, California, USA]) (5).

Indirect immunofluorescence staining was performed to characterize the isolated cells. The reagents used included: rabbit polyclonal anti-human vWF (diluted 1/2,000; DAKO Corp., Carpinteria, California, USA) with nonimmune rabbit IgG as a control; mouse monoclonal anti-human E-selectin $\operatorname{IgG}_{1}$ (clone 4B12;5 $\mu \mathrm{g} / \mathrm{ml}$; kindly provided by D. Hollenbaugh, Bristol-Myers Squibb) (7) mouse monoclonal anti-CD31/PECAM-1 IgG 1 (DAKO, Carpinteria, CA), with an isotype-matched control mouse $\mathrm{IgG}_{1}(5 \mu \mathrm{g} / \mathrm{ml}$; Becton Dickinson, Bedford, Massachusetts, USA) as a control; biotinylated goat anti-rabbit $\mathrm{IgG}_{1}$, biotinylated horse anti-mouse IgG, and fluoresceinconjugated avidin (Vector Laboratories Inc.). In addition, we used anti-KDR (Flk1; Santa Cruz Biotechnology Inc., Santa Cruz, California, USA), and mouse anti-human smooth muscle cell $\alpha$-actin (Sigma Chemical Co.) to stain many of the EC and UBC samples.

For immunostaining, cells were grown in EBM-B on gelatin-coated glass coverslips, washed in PBS containing $1.26 \mathrm{mM} \mathrm{CaCl}_{2}$ and $0.8 \mathrm{mM} \mathrm{MgSO}_{4}$, and fixed with methanol for 10 minutes on ice. Immunostaining was performed at room temperature, and cells were washed three times in PBS after each step. PBS with 1\% BSA was used for antibody dilution. Cells were mounted with Fluoromount G (Southern Biotechnology Associates Inc., Birmingham, Alabama, USA) and observed at 400× with an Axiophot II fluorescence microscope (Zeiss, Oberkochen, Germany). Photographs were taken with Kodak TMAX p3200 film (Eastman Kodak Co., Rochester, New York, USA).

DNA isolation and clonality assay. The Puregene DNA isolation Kit (Gentra Systems Inc., Minneapolis, Minnesota, USA) was used to extract DNA, according to the manufacturer's instructions, from peripheral blood leukocytes (PBLs) of 40 control individuals and from cultured ECs at passages 4-7 from ten hemangioma lesions $(1,4,5,10,12,13,17 \mathrm{~A}, 17 \mathrm{~B}, 20$, and 21$)$, four hemangioendothelioma lesions (8B, 8C, 8F, and 8G), and five normal skin samples. In addition, DNA was isolated from the cultured unbound fibroblast-like cells (UBCs) from hemangioma lesions 1 and 10.

Paraffin-embedded tissue sections of myometrium and leiomyomata from hysterectomy specimens were provided by B. Quade (Department of Pathology, Brigham and Women's Hospital, Boston, Massachusetts, USA). These samples, previously shown to be clonal (8), were deparaffinized, proteinase K-treated, and used as a positive controls for the HUMARA assay.

We analyzed these DNA samples for clonality using the X-linked human androgen receptor gene (HUMARA) assay described by Allen et al. (9). Exon 1 of the HUMARA gene contains a highly $(90 \%)$ polymorphic CAG short tandem repeat (STR) (11-31 copies) with adjacent $H h a \mathrm{I}$ and $H p a I$ sites, at which methylation correlates with X-chromosome inactivation. In females heterozygous at this allele, STR size polymorphism distinguishes the maternal and paternal X chromosomes, and digestion with methylation-sensitive HhaI distinguishes between the unmethylated, active $X$, which is cut, and the methylated, inactive $\mathrm{X}$, which is not.

A total of $5 \mu \mathrm{g}$ of DNA was digested in a $50-\mu \mathrm{l}$ reaction with 20 units of HhaI (New England Biolabs Inc., Beverly, Massachusetts, USA) at $37^{\circ} \mathrm{C}$ for up to 24 hours. For 
each sample, PCR was performed on $1 \mu \mathrm{l}$ of the digest and $50 \mathrm{ng}$ of undigested DNA. PCR reactions $(50 \mu \mathrm{l})$ contained $20 \mathrm{nM}$ each of primers: H1 5'-GCT GTG AAG GTT GCT GTT CCT CAT- $3^{\prime}$ and H2 $5^{\prime}$-TCC AGA ATC TGT TCC AGA GCG TGC- $3^{\prime}(9)$ and $0.5 \mu l \alpha-33 P$ dATP (1,000-3,000 Ci/mmol, $10 \mathrm{mCi} / \mathrm{ml}$; ICN Radiochemicals Inc., Irvine, California, USA). The amplification was carried out with 0.5 units of Taq DNA Polymerase (QIAGEN Inc., Valencia, California, USA) in a 10X buffer, containing $15 \mathrm{mM} \mathrm{MgCl}_{2}$, supplied by the manufacturer. The PCR conditions were as follows: an initial denaturation at $93^{\circ} \mathrm{C}$ for 3 minutes, followed by 30 cycles of denaturation at $93^{\circ} \mathrm{C}$ for 40 seconds, annealing at $65^{\circ} \mathrm{C}$ for $40 \mathrm{sec}-$ onds, and extension at $72^{\circ} \mathrm{C}$ for 40 seconds. These steps were followed by a final extension at $72^{\circ} \mathrm{C}$ for 5 minutes.

The PCR products were electrophoresed in an $8 \%$ nondenaturing polyacrylamide gel (Accugel 29:1; National Diagnostics, Atlanta, Georgia, USA) at $600 \mathrm{~V}$ for approximately 10 hours and visualized by exposure to autoradiographic film (Eastman Kodak Co.) or phosphorimaging screens (Fuji Medical Systems Inc., Stamford, Connecticut, USA).

An initial PCR was used to look for informative alleles and homozygous individuals were excluded from the study. The NIH Image (version 1.62) software was used to obtain densitometric scans for each lane on the gels. Defined bands representing the different CAG alleles were seen as major peaks that could be easily distinguished from "stutter" bands, seen as minor peaks slightly out of phase with the main peaks. The intensity of each band and its stutter bands was determined as the total area under the corresponding peaks in the densitometric tracing. The ratio of the least intense to the most intense CAG allele in each heterozygous sample represented the amplification ratio. A ratio of 1.00 represents random X-inactivation; a ratio of 0.00 represents complete skewing and monoclonality. Amplification ratios determined before and after Hhal digestion were compared as a measure of clonality.
On the basis of other studies $(10,11)$ and a comparison with samples of leiomyomata previously shown to be clonal (see earlier discussion here), we defined samples as clonal when there was significant skewing toward one allele after $\mathrm{HbaI}$ digestion, so that the amplification ratio of the minor allele to the predominant allele was 0.45 , corresponding to a ratio between the two alleles of about 30:70.

Cell proliferation assay. ECs were plated onto gelatincoated 24-well plates at a density of 8,000 cells per 2 $\mathrm{cm}^{2}$ well in EBM131 medium with 5\% FBS and $2 \mathrm{mM}$ glutamine, $100 \mathrm{U} / \mathrm{ml}$ penicillin, and $100 \mu \mathrm{g} / \mathrm{ml} \mathrm{strep-}$ tomycin. The following day, the plating efficiencies of the cells were determined and the proliferation of HDMECs and hemECs were compared after a 48-hour incubation with $1 \mathrm{ng} / \mathrm{ml} \mathrm{bFGF}$ or $10 \mathrm{ng} / \mathrm{ml} \mathrm{VEGF}$ (R\&D Systems Inc., Minneapolis, Minnesota, USA) at $37^{\circ} \mathrm{C}$ with $5 \% \mathrm{CO}_{2}$. Assays were performed in quadruplicate, and cells were counted in a Coulter counter. The results were expressed as mean $\pm \mathrm{SD}$.

Cell migration and endostatin response assays. Migration assays for ECs were performed in a standard 48-well chemotaxis chamber (Neuro Probe Inc., Gaithersburg, Maryland, USA) according to the method described by Yamaguchi et al. (12). HemECs and HDMECs were assayed in EBM131 medium containing $2 \mathrm{mM}$ glutamine, $100 \mathrm{U} / \mathrm{ml}$ penicillin, $100 \mu \mathrm{g} / \mathrm{ml}$ streptomycin, and $0.025 \%$ BSA. A total of 10,000 cells per well were placed in the upper chamber and their migration across a Nucleopore polyvinylpyrrolidone-free polycarbonate membrane (Corning-Costar Corp., Cambridge, Massachusetts, USA) with $8-\mu \mathrm{m}$ pores was stimulated with $5 \mathrm{ng} / \mathrm{ml} \mathrm{VEGF}_{165}$ (R\&D Systems Inc.) in EBM131 with $0.025 \%$ BSA, placed in the lower chamber. Assays were performed in quadruplicate for 4-6 hours, and the migrated cells, adhered to the underside of the membrane, were stained with DiffQuick stain (VWR Scientific Products, Bridgeport, New Jersey, USA); nuclei were counted using a light microscope. Results were plotted as mean \pm SD.

Table 1

Clinical data: ages of patients at the time of resection of each lesion, location and size of the lesions, and other relevant information

\begin{tabular}{|c|c|c|c|c|}
\hline Patient number & Lesions & Age at time of resection & Location and size & Comments \\
\hline 1 & hemEC-1 & 8 months & $1.8 \times 0.8 \mathrm{~cm}$, right eyelid & Normal karyotype $\mathrm{A}^{\mathrm{A}}$ \\
\hline 4 & hemEC-4 & 3 months & $3 \times 3 \mathrm{~cm}$, right flank & \\
\hline 5 & hemEC-5 & 4 months & $5 \mathrm{~mm}$, lower abdomen & Multiple hemangiomas \\
\hline 8 & $\begin{array}{l}\text { heomaEC-8B } \\
\text { heomaEC-8C } \\
\text { heomaEC-8F } \\
\text { heomaEC-8G }\end{array}$ & 2 years & $\begin{array}{l}\text { B - ankle } \\
\text { C - knee } \\
\text { F - right foot } \\
\text { G - inner thigh }\end{array}$ & $\begin{array}{c}\text { Normal karyotype }{ }^{A} \text {, multiple } \\
\text { hemangioendothelioma lesions } \\
\text { of variable size, new lesions still } \\
\text { appearing at } 2 \text { years }\end{array}$ \\
\hline 10 & hemEC-10 & 2 years & $4 \mathrm{~cm}$, forehead & \\
\hline 12 & hemEC-12 & 4 months & $1.5 \mathrm{~cm}$, left cheek & \\
\hline 13 & hemEC-13 & 9 months & $3 \mathrm{~cm}$, left upper eyelid & Other hemangiomas on neck and labia \\
\hline 17 & $\begin{array}{l}\text { hemEC-17A } \\
\text { hemEC-17B }\end{array}$ & 10 months & $\begin{array}{l}\text { A: } 3 \mathrm{~cm} \text {, scalp } \\
\text { B: } 3.5 \times 4 \mathrm{~cm} \text {, forehead }\end{array}$ & \\
\hline 20 & hemEC-20 & 8 months & $2.5 \mathrm{~cm}$, neck & Multiple hemangiomas \\
\hline 21 & hemEC-21 & 9 months & $6.5 \times 5.5 \mathrm{~cm}$, scalp & $\begin{array}{l}\text { Other hemangiomas on } \\
\text { right ear and forehead }\end{array}$ \\
\hline
\end{tabular}

${ }^{A} E C s$ from these patients showed a normal $(46, X X)$ karyotype. 
EC samples were pretreated with human recombinant endostatin (hES) prepared as described previously (12), at concentrations of 1,10 , and $100 \mathrm{ng} / \mathrm{ml}$, by incubation at $37^{\circ} \mathrm{C}$ for 30 minutes, and the migration assay was performed as already described here.

\section{Results}

Clinical data. As summarized in Table 1, the patients selected for the study ranged in age from 3 to 26 months at the time of resection of their hemangioma; three of nine had multiple lesions. Patient 8 had more than 100 rapidly proliferating vascular lesions at age 2 years, and new lesions continued to appear. The lesions failed to respond to drugs used to treat hemangioma, such as corticosteroid, IFN $\alpha-2 b$, and cyclophosphamide. Furthermore, resected tissue from the lesions did not react with anti-GLUT1 antibodies (H. Kozakewich, personal communication), as has been described for the majority of hemangiomas (13). Therefore, these lesions have been described as hemangioendotheliomas. Additional evidence that this patient's tumors were not hemangiomas was provided by the response of ECs to endostatin (see later here), which is the opposite of that for the hemangioma cell samples.

Characterization of isolated ECs. To verify that the isolated Ulex europaeus I bead-bound cells (see Methods) were indeed endothelial and free from contaminating non-ECs, we analyzed expression of endothelial-specific markers vWF, CD31/PECAM-1, and E-selectin by indirect immunofluorescence. hemEC-1 exhibited punctate cytoplasmic staining with anti-vWF (Figure 1a), consistent with localization of vWF in WeibelPalade bodies, a definitive feature of ECs. CD31/PECAM-1 was seen concentrated at cell-cell borders (Figure 1b), consistent with its role as a cell adhesion molecule. To upregulate E-selectin, hemEC-1 cells were treated with LPS before immunostaining. Eselectin was readily detected upon LPS induction (Fig- ure 1c), providing further confirmation of an endothelial phenotype. Diffuse background staining was observed with a isotype-matched control IgG1 (Figure 1d). HemECs from all patients showed similar patterns of expression of vWF, CD31, and inducible E-selectin, and in addition, expressed other markers of the endothelial lineage such as KDR, TIE-2, and VE-cadherin (data not shown) but did not express the mesenchymal cell marker, smooth muscle $\alpha$-actin.

In hemEC-12 and hemEC-17A, 10-30\% of the cells appeared to be $\mathrm{vWF}$ and $\mathrm{CD}-31$ negative, indicating that these cultures were contaminated with UBCs. Cultures of unbound cells from hemangiomas 1 and 10 were also negative for EC markers $\mathrm{VWF}$ or CD31. HemEC-12 was reselected with Ulex europaeus I-coated beads to give an essentially pure EC culture.

Clonality of hemangioma ECs. The experimental design for assessing clonality, using the X-linked human androgen receptor (HUMARA) gene is described in Methods. A DNA sample from each individual was first tested for heterozygosity of HUMARA STRs, by direct amplification using primers $\mathrm{H} 1$ and $\mathrm{H} 2$. Patients 5 and 13 , as well as ten of 40 control blood leukocyte samples, were excluded because they were found to be homozygous. This is about twice the $10 \%$ homozygosity previously reported for this allele $(9,14)$. Blood leukocyte DNA from the remaining 30 controls was digested with Hha $\mathrm{I}$ and then amplified with $\mathrm{H} 1$ and $\mathrm{H} 2$ primers.

The results demonstrated that $30 \%(9 / 30)$ of the 30 normal control samples had skewed $\mathrm{X}$ chromosome inactivation in their blood cells, confirming a previous report (15), and suggesting that X-inactivation patterns are tissue specific. Thus, PBLs would be poor controls for study of clonality in cutaneous endothelium. Therefore, we decided to use human dermal derived ECs from normal female skin (HFSECs) as controls. Ethical considerations prevented us from obtaining such cells from the hemangioma patients in the study, so we

\section{Figure 1}

Characterization of hemangiomaderived endothelial cells by indirect immunofluorescence. Hemangiomaderived endothelial cells (hemEC-1) were fixed with methanol and incubated with anti-vWF (a), antiCD31/PECAM-1 (b), anti-E-selectin (c), or isotype-matched control mouse $\lg G_{1}(d)$. Endothelial cells in c were activated with $0.2 \mathrm{ng} / \mathrm{ml}$ LPS for 5 hours to upregulate E-selectin (22). Bar, $10 \mu \mathrm{m}$.
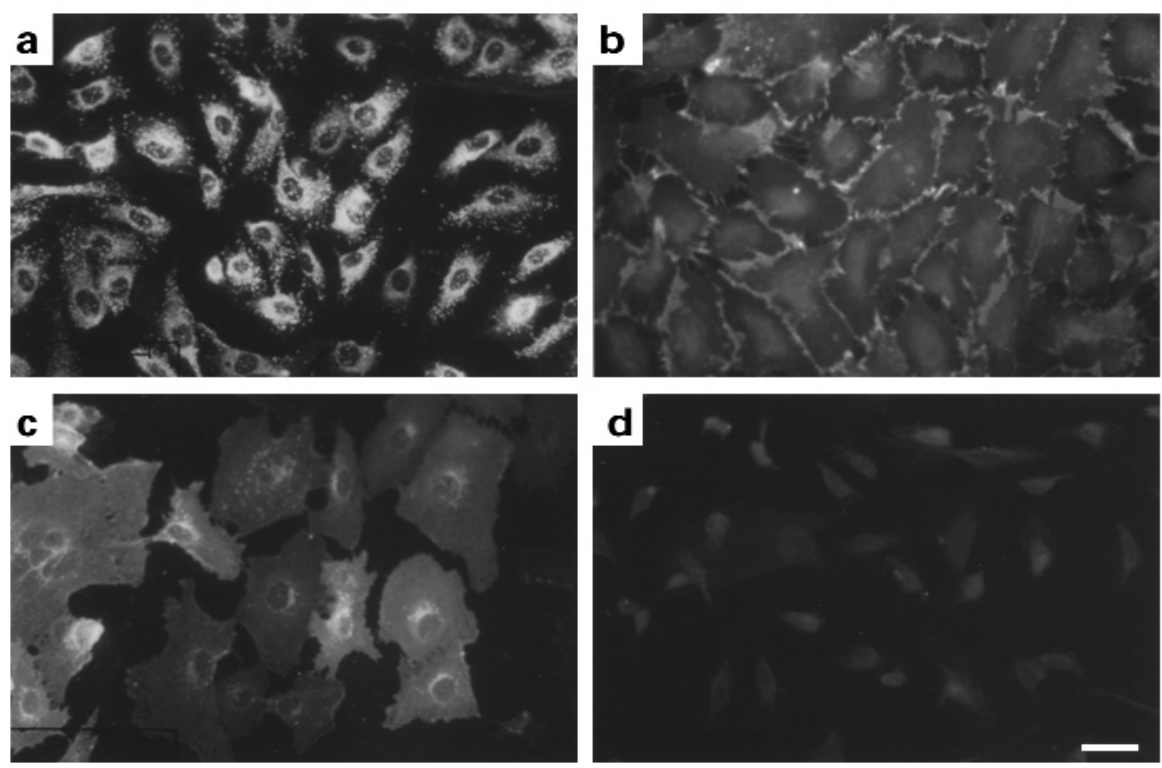
obtained them from skin of age-matched unrelated female patients, as described in Methods. Isolated ECs from hemangioma patients and five controls were subjected to HUMARA assay. Cells were analyzed at sequential trypsin passages (P4, P5, P6, and P7) to ensure that the cells were not becoming clonal as a result of the prolonged culturing process. For each DNA sample, two independent $\mathrm{HhaI}$ digests and products of at least two independent amplification reactions from each digest were analyzed. Table 2 shows the mean amplification ratios of the HUMARA alleles and standard deviations; a ratio of 0.45 or less was considered to represent clonality. In three of five $(60 \%)$ of the control EC samples (HFSEC 3, 4, 11), both X chromosomes were equally amplified, at all passages tested (P4 to P7, Figure $2 \mathrm{a}$ ), whereas two of the control samples (HFSEC 1 and 10) exhibited skewing. ECs from all eight (100\%) hemangioma lesions showed similarly significant skewing to one allele, indicating clonality of those cell populations (Figure $2 \mathrm{~b}$ ). In contrast, UBCs from hemangiomas 1 and 10 showed almost equal amplification of both $\mathrm{X}$ chromosomes (Figure 2c).

Hemangioma lesions 1, 4, 10, 17B, 20, and 21 showed complete absence of one allele (Figure $2 \mathrm{~b}$ ). Lesions 12 and 17A initially showed significant, but not complete, skewing toward one of the two alleles. Staining of hemEC-12 and -17A suggested some contamination with UBCs (see earlier discussion here). To determine whether this contamination could contribute to the incomplete skewing, hemEC-12 was reselected (see Methods) and reassayed for clonality. After reselection, hemEC-12r showed complete skewing (Table 2).

DNA from five of eight lesions exhibited skewing to the larger of the two alleles; the remaining three showed skewing to the smaller allele (Table 2). Two lesions from patient 17 had discordant skewing. In summary, these data demonstrate that all hemangiomas studied here are clonal.

Differences in rates of proliferation and migration between HDMECs and hemECs. Proliferation and migration of some hemECs were measured in comparison to that of HDMEC samples from infant foreskin that had been isolated and cultured under identical conditions. Given that it is well known that clones of normal ECs can exhibit variations in growth rate and respond differently to growth factors (16), hemEC samples were compared with six different control samples (HDMECs) for proliferation and/or migration properties.

The results of proliferation assays are shown in Figure 3. HemEC-1, hemEC-4, heomaEC-8, and hemEC17 cells proliferated approximately 2.5 times faster than did HDMECs, both in the presence or absence of exogenous bFGF at $1 \mathrm{ng} / \mathrm{ml}$. This difference was maintained with continued passaging of cells, at least up to passage 11 (data not shown). HemECs and HDMECs did not appear to differ in the degree to which they were stimulated by bFGF, however, indicating that hemEC cells are not producing saturating concentrations of bFGF. HemEC-1 (Figure 3a), hemEC-4, heo- a
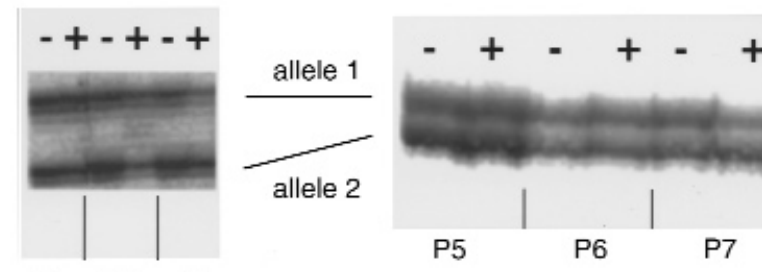

P4 P5 P6

b

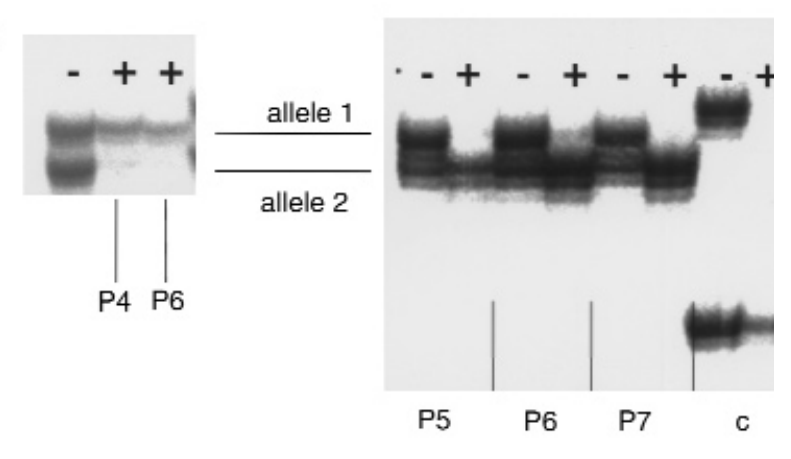

c

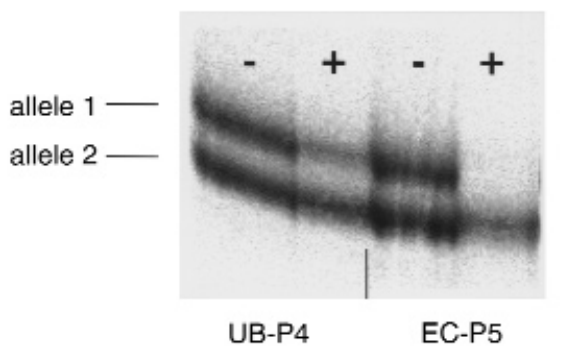

Figure 2

Results of HUMARA assay on DNA from ECs of control infants' skin, hemangioma lesions, and unbound fibroblast-like cells. Amplification was performed before (-) or after $(+)$ Hhal digestion. For each cell sample shown, the individual is heterozygous for CAG repeat size and has two different alleles before Hhal digestion, represented by two major PCR products on gel. Fainter ("stutter") bands are products of slippage by DNA polymerase in STR region. (a) Amplification of DNA from ECs cultured at P4 to P7 from skin of two control female infants HFSEC-3 (left) and HFSEC-11 (right). In each sample, two alleles are equally amplifiable both before and after digestion. (b) Amplification of DNA from cultured hemECs from patient 1 (left) at P4 and P6 and patient 21 (right) at P5, P6, and P7. In both cases, one allele completely disappears after Hhal digestion. This selective amplification of one allele indicates that it is always methylated and not subject to digestion by Hhal and, therefore, is the only inactive allele in cell population. $C$ is a positive control for the HUMARA assay. (c) Amplification of DNA from cultured unbound, fibroblast-like cells of hemangioma 10 at P4 (UB-P4). For comparison, DNA from cultured hemEC-10 at P5 (EC-P5) is shown at right.

maEC-8, and hemEC-17 also proliferated three times faster than HDMECs in response to $10 \mathrm{ng} / \mathrm{ml}$ VEGF. The increased proliferation rate was also observed when the cells were plated in gelatin-, fibronectin-, or type IV collagen-coated culture wells (data not shown).

In migration assays, hemEC-1 (Figure 3b), hemEC10 , and hemEC-21 cells showed an approximately 3.5fold better response than did different HDMECs in the presence of $5 \mathrm{ng} / \mathrm{ml}$ VEGF. These data demonstrate that hemECs derived from infantile hemangiomas 
a

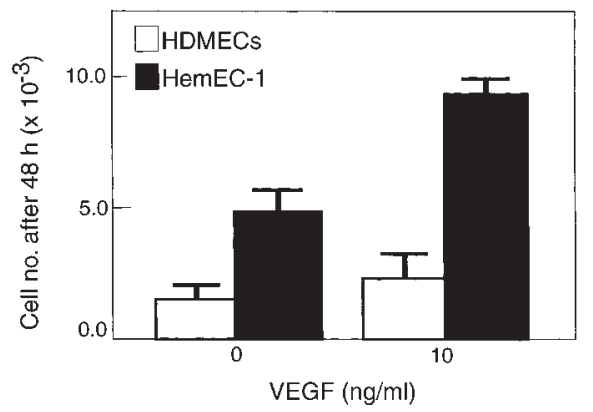

b

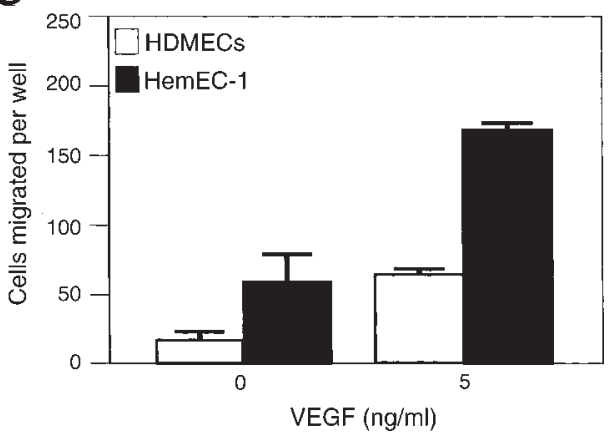

Figure 3

Comparison of in vitro properties of HDMECs vs. hemEC-1. (a) Comparison of proliferation rates of HDMECs vs. hemEC-1 in response to VEGF. HemEC-1 cells proliferate approximately 2.5 -fold faster than HDMECs, both in the presence $(10 \mathrm{ng} / \mathrm{ml})$ or absence of exogenous VEGF. (b) Comparison of VEGF-induced migration of HDMECs vs. hemEC-1. HemEC-1 cells migrate approximately 3.5-fold faster than do HDMECs with $(10 \mathrm{ng} / \mathrm{ml})$ or without VEGF stimulation.

retain altered proliferation and migration responses when removed from their in vivo environment. This is consistent with the clonality data and supports the hypothesis that the defect is intrinsic to the ECs.

Altered migratory response of hemECs to endostatin. In light of these observations, we tested whether the increased migration was influenced by the angiogenesis inhibitor, endostatin (hES). Figure 4 shows the surprising result obtained. In contrast to the inhibition of migration effected by hES on HDMECs (Figure 4a) and other EC types in the presence of VEGF (12), hemEC-1 (Figure 4b), hemEC-10, and hemEC-21 cells

Table 2

Results of clonality assay showing the mean amplification ratios of the smaller to larger HUMARA alleles, obtained at various passages, for each sample. The predominant allele in each case is also indicated.

\begin{tabular}{lccc}
\hline Cell sample & $\begin{array}{c}\text { Average } \\
\text { amplification ratio }\end{array}$ & $\begin{array}{c}\text { Standard } \\
\text { deviation }\end{array}$ & $\begin{array}{c}\text { Predominant } \\
\text { allele }\end{array}$ \\
HFSEC-1 & 0.00 & 0.00 & $\mathrm{~S}$ \\
HFSEC-3 & 0.84 & 0.10 & - \\
HFSEC-4 & 0.84 & 0.07 & - \\
HFSEC-10 & 0.02 & 0.00 & $\mathrm{~S}$ \\
HFSEC-11 & 0.96 & 0.06 & - \\
hemEC-1 & 0.02 & 0.00 & $\mathrm{~L}$ \\
hemEC-4 & 0.02 & 0.01 & $\mathrm{~L}$ \\
heomaEC-8B & 0.02 & 0.03 & $\mathrm{~S}$ \\
heomaEC-8C & 0.06 & 0.01 & $\mathrm{~S}$ \\
heomaEC-8F & 0.01 & 0.01 & $\mathrm{~S}$ \\
heomaEC-8G & 0.02 & 0.05 & $\mathrm{~S}$ \\
hemEC-10 & 0.05 & 0.08 & $\mathrm{~S}$ \\
hemEC-12 & 0.43 & 0.17 & $\mathrm{~L}$ \\
hemEC-12r & 0.01 & 0.01 & $\mathrm{~L}$ \\
hemEC-17A & 0.43 & 0.10 & $\mathrm{~S}$ \\
hemEC-17B & 0.05 & 0.06 & $\mathrm{~L}$ \\
hemEC-20 & 0.04 & 0.08 & $\mathrm{~L}$ \\
hemEC-21 & 0.02 & 0.04 & $\mathrm{~S}$ \\
UBC-1 & 0.85 & 0.04 & - \\
UBC-10 & 0.91 & 0.07 & - \\
\hline
\end{tabular}

L, larger allele, S, smaller allele. were stimulated in their migration toward VEGF in a dose-dependent manner, even at concentrations of 1 $\mathrm{ng} / \mathrm{ml}$ of endostatin.

Patient 8. Patient 8 was included in the study on the basis of having multiple rapidly proliferating vascular lesions described as high-grade hemangioendothelioma (heoma). Clonality analysis showed skewing toward the smaller allele in heomaECs isolated from a number of lesions (8B, 8C, 8F, and 8G) resected from different parts of her body. ECs from this patient proliferated and migrated faster than normal, like the hemECs, but they also behaved similarly to control ECs, in that they were inhibited by hES in their VEGFstimulated migration (Figure 4c).

\section{Discussion}

Identification of factors that trigger and arrest the growth of hemangiomas will be invaluable in our understanding of vasculogenic and angiogenic processes and related diseases. We hypothesize that whatever these factors are, they control EC proliferation and are altered as a result of somatic mutations. The results presented here are consistent with this hypothesis. We have isolated cells that express EC specific markers, such as vWF, E-selectin, and CD31/PECAM-1, from proliferating hemangiomas and we have found that seven of seven patients have lesions that are clonal in nature. We provide further support for this hypothesis by showing that hemangioma cells proliferate and migrate more rapidly than normal ECs, as would be predicted from the nature of the lesions. These characteristics are maintained even when the cells are removed from their physiological environment and are consistent when compared with several different normal EC samples, which themselves may exhibit a large degree of variation in growth rate and response to growth factors (16).

The finding of discordance of $\mathrm{X}$-inactivation patterns in two lesions from the same individual (patient 17) could be explained by a mutation that occurred relatively early in development before the establishment of 
a

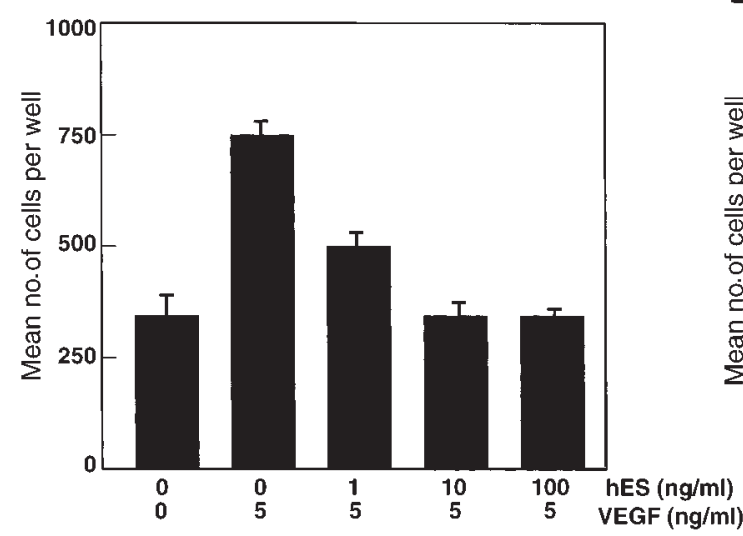

b

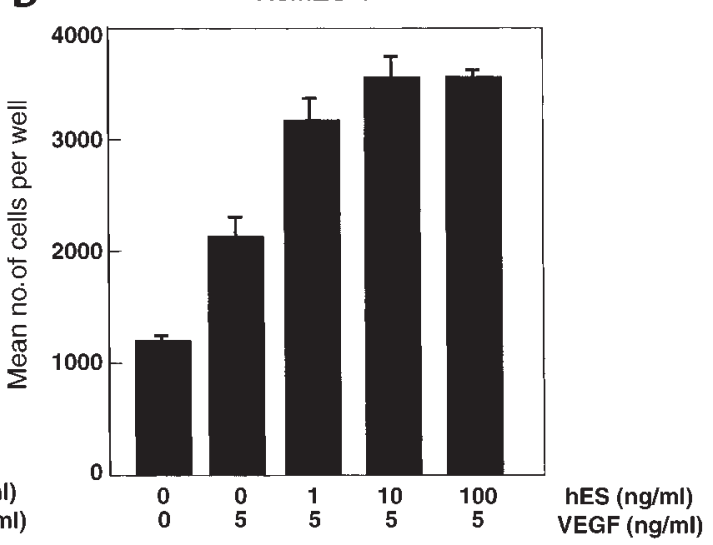

Figure 4

Effect of hES on VEGF-induced migration of HDMECs, hemEC-1, and heomaEC-8B. (a) Migration of HDMECs is inhibited by hES. Complete inhibition is achieved at approximately $10 \mathrm{ng} / \mathrm{ml}$ hES. (b) HemEC-1 cells exhibit the opposite response to the other cells; their migration is strongly stimulated by hES even at $1 \mathrm{ng} / \mathrm{ml}$. (c) Migration of heomaEC-8B is inhibited by hES.

permanent $\mathrm{X}$-inactivation; alternatively, it could be the result of two independent mutations. Because hemangioma occurs in up to $10 \%$ of Caucasian infants, two hemangiomas caused by independent mutations in one individual would be relatively common as well.

Previous studies $(17,18)$ demonstrate that normal tissues can contain fairly large patches of cells that are uniform with respect to $\mathrm{X}$-chromosome inactivation. These include the aorta and coronary arteries (19), where clonal patches of developmental origin exist for smooth muscle cells. Such monoclonal regions can explain why a significant fraction $(\sim 30 \%)$ of aortic tissue samples show skewing in HUMARA assays (19). Although such data are not available for vascular ECs, we assume that similar developmental patches may exist. This would explain why two of five (40\%) of the normal EC samples showed monoclonality. Given this frequency of clonality in the control samples, the likelihood that all the hemangioma samples would show clonality by chance is less than $10^{-3}$. We conclude, therefore, that the uniform Xinactivation patterns seen in hemangiomas are consequences of the disease process. Non-ECs within the lesions are likely to be normal, as the unbound fibroblast-like cells isolated from several lesions showed random $\mathrm{X}$-inactivation patterns.

Endothelium is generally quiescent under normal physiological conditions after birth, but will undergo localized proliferation in response to specific physiological or pathological stimuli, such as injury or tumor growth. Angiogenesis can be halted and the quiescent state restored by antiangiogenic stimuli, suggesting that it is a tightly regulated process, controlled locally by the levels of angiogenic and antiangiogenic factors c

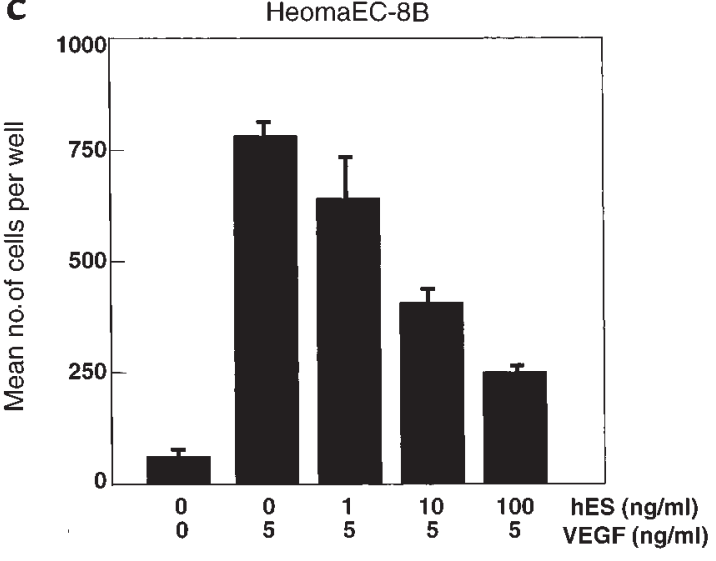

(20). Changes in the balance of these factors, due to alterations in the factors themselves or in regulatory molecules, can effect these angiogenic responses. For example, in hemangioma, an anomalous stimulus produced by an abnormality of regulation or expression of a specific gene that controls EC proliferation could cause abnormal angiogenesis, with subsequent activation of EC apoptosis (2).

Walter et al. (21) presented evidence for linkage in three familial cases of hemangioma to chromosome 5q, in a region containing three genes involved in vessel growth: PDGF-R $\beta, F G F R-4$, and FLT-4. Several other genes and their protein products are known to be involved in EC proliferation and angiogenic regulation, including inducers, such as FGFs, VEGF, and ANG1, and inhibitors, such as angiostatin, endostatin, and thrombospondin (20). These are all obvious candidates, mutations in which could produce the abnormal vessel growth seen in hemangioma. Alternatively, mutations in upstream or downstream targets of these genes could produce the same effect.

The response of hemECs to the angiogenesis inhibitor hES was unexpected. VEGF-induced migration in three of three hemEC samples tested was stimulated instead of inhibited by hES. It has been reported that VEGF-induced migration of ECs is inhibited by hES at various concentrations and under different conditions (12), suggesting that hES and VEGF may regu- 
late a common signaling pathway for migration. In this pathway, hES may control a rate-limiting step that results in the inhibition of VEGF-stimulated migration. Conceivably, alterations in signaling pathways downstream of the VEGF-receptor in hemangioma ECs, as a result of a somatic mutation, could convert the inhibitory effect of endostatin to one of stimulation. The inhibitory effect of hES on ECs from patient 8 may prove useful as an experimental tool, as it enabled us to clearly distinguish this patient's tumors from other typical hemangiomas.

We believe our data provide strong support for the hypothesis that hemangiomas are caused by an intrinsic abnormality of ECs. However, it is possible, that all hemangiomas are not due to the same underlying defect. Thus in some cases, the primary defect could exist external to the proliferating ECs as suggested by Berard et al. (4). It is also possible that even in hemangiomas caused by somatic mutations in ECs, different genes may be involved in different patients. Elucidation of the mutated genes in each case will enhance our understanding of the molecular control of EC proliferation, and the potential for antiangiogenic treatment of hemangiomas.

\section{Acknowledgments}

We thank Brad Quade for providing us with control samples and helpful advice for the HUMARA assay. This work was supported by a grant from the NIH (AR 36820 to B.R. Olsen). E. Boye was supported by the John Butler Mulliken Foundation. Y. Yu, G. Paranya, and J. Bischoff were supported by grants from the Gackstatter Foundation and the Charlotte Geyer Foundation.

1. Mulliken, J.B. 1988. Diagnosis and natural history of hemangiomas. In Vascular birthmarks: hemangiomas and malformations. J.B. Mulliken and A.E. Young, editors. W.B. Saunders Co. Philadelphia, Pennsylvania, USA. 41-62.

2. Razon, M.J., Kräling, B.M., Mulliken, J.B., and Bischoff, J. 1998. Increased apoptosis coincides with onset of involution in infantile hemangioma. Microcirculation. 5:189-195.
3. Mulliken, J.B., Fishman, S.J., and Burrows, P.E. 2000. Vascular anomalies. In Current problems in surgery. S.A. Wells and L.L. Creswell, editors. Mosby. St. Louis, Missouri, USA. 517-584.

4. Berard, M., et al. 1997. Vascular endothelial growth factor confers a growth advantage in vitro and in vivo to stromal cells cultured from neonatal hemangiomas. Am. J. Pathol. 150:1315-1326.

5. Kräling, B.M., and Bischoff, J. 1998. A simplified method for growth of human microvascular endothelial cells results in decreased senescence and continued responsiveness to cytokines and growth factors. In Vitro Cell. Dev. Biol. Anim. 34:308-315.

6. Jackson, C.J., Garbett, P.K., Nissen, B., and Schrieber, L. 1990. Binding of human endothelium to Ulex europaeus I-coated Dynabeads: application to the isolation of microvascular endothelium. J. Cell Sci. 96:257-262.

7. Kräling, B.M., et al. 1996. E-selectin is present in proliferating endothelial cells in human hemangiomas. Am. J. Pathol. 148:1181-1191.

8. Quade, B.J., et al. 1997. Disseminated peritoneal leiomyomatosis. Clonality analysis by $\mathrm{X}$ chromosome inactivation and cytogenetics of a clinically benign smooth muscle proliferation. Am. J. Pathol. 150:2153-2166.

9. Allen, R.C., Zoghbi, H.Y., Moseley, A.B., Rosenblatt, H.M., and Belmont, J.W. 1992. Methylation of HpaII and HhaI sites near the polymorphic CAG repeat in the human androgen-receptor gene correlates with $\mathrm{X}$ chromosome inactivation. Am. J. Hum. Genet. 51:1229-1239.

10. Murry, C.E., Gipaya, C.T., Bartosek, T., Benditt, E.P., and Schwartz, S.M. 1997. Monoclonality of smooth muscle cells in human atherosclerosis. Am. J. Pathol. 151:697-705.

11. Lee, S.D., et al. 1998. Monoclonal endothelial cell proliferation is present in primary but not secondary pulmonary hypertension. J. Clin. Invest. 101:927-934.

12. Yamaguchi, N., et al. 1999. Endostatin inhibits VEGF-induced endothelial cell migration and tumor growth independently of zinc binding. EMBOJ. 18:4414-4423.

13. North, P.E., Waner, M., Mizeracki, A., and Mihm, M.C., Jr. 2000. GLUT1: a newly discovered immunohistochemical marker for juvenile hemangiomas. Hum. Pathol. 31:11-22.

14. Edwards, A., Hammond, H.A., Jin, L., Caskey, C.T., and Chakraborty, R. 1992. Genetic variation at five trimeric and tetrameric tandem repeat loci in four human population groups. Genomics. 12:241-253.

15. Gale, R.E., Wheadon, H., Boulos, P., and Linch, D.C. 1994. Tissue specificity of X-chromosome inactivation patterns. Blood. 83:2899-2905.

16. Tsuboi, R., Sato, Y., and Rifkin, D.B. 1990. Correlation of cell migration, cell invasion, receptor number, proteinase production, and basic fibroblast growth factor levels in endothelial cells. J. Cell Biol. 110:511-517.

17. Linder, D., and Gartler, S.M. 1965. Distribution of glucose-6-phosphate dehydrogenase electrophoretic variants in different tissues of heterozygotes. Am. J. Hum. Genet. 17:212-220.

18. Tsai, Y.C., et al. 1995. Mosaicism in human epithelium: macroscopic monoclonal patches cover the urothelium. J. Urol. 153:1697-1700.

19. Chung, I.M., Schwartz, S.M., and Murry, C.E. 1998. Clonal architecture of normal and atherosclerotic aorta: implications for atherogenesis and vascular development. Am. J. Pathol. 152:913-923.

20. Talks, K.L., and Harris, A.L. 2000. Current status of antiangiogenic factors. Br. J. Haematol. 109:477-489.

21. Walter, J.W., et al. 1999. Genetic mapping of a novel familial form of infantile hemangioma. Am. J. Med. Genet. 82:77-83.

22. Bevilacqua, M.P., and Nelson, R.M. 1993. Selectins. J. Clin. Invest. 91:379-387. 